\title{
Definition of medication-related osteonecrosis of the jaw in 2014
}

Salvatore L. Ruggiero, Thomas B. Dodson, John Fantasia, Reginald Goodday, Tara Aghaloo, Bhoomi Mehrotra, Felice O'Rayn

\section{Source}

Salvatore L. Ruggiero, Thomas B. Dodson, John Fantasia, Reginald Goodday, Tara Aghaloo, Bhoomi Mehrotra. (2014). American Association of Oral and Maxillofacial Surgeons Position Paper on Medication-Related Osteonecrosis of the Jaw-2014 Update. Journal of Oral and Maxillofacial Surgery, vol. 72 (10), 1938-1956.

1. Current or previous treatment with antiresorptive or antiangiogenic agents

2. Exposed bone or bone that can be probed through an intraoral or extraoral fistula(e) in the maxillofacial region that has persisted for more than 8 weeks

3. No history of radiation therapy to the jaws or obvious metastatic disease of the jaws 